\title{
Tenascin-C Contains Domains That Independently Regulate Neurite Outgrowth and Neurite Guidance
}

\author{
Sally Meiners, Mary Lynn T. Mercado, Mohammed S. A. Nur-e-Kamal, and Herbert M. Geller \\ Department of Pharmacology, University of Medicine and Dentistry of New Jersey, Robert Wood Johnson Medical \\ School, Piscataway, New Jersey 08854
}

Tenascin- $C$ has been implicated in regulation of both neurite outgrowth and neurite guidance. We have shown previously that a particular region of tenascin- $C$ has powerful neurite outgrowth-promoting actions in vitro. This region consists of the alternatively spliced fibronectin type-III (FN-III) repeats A-D and is abbreviated fnA-D. The purpose of this study was to investigate whether fnA-D also provides neurite guidance cues and whether the same or different sequences mediate outgrowth and guidance. We developed an assay to quantify neurite behavior at sharp substrate boundaries and found that neurites demonstrated a strong preference for fnA-D when given a choice at a poly-L-lysine-fnA-D interface, even when fnA-D was intermingled with otherwise repellant molecules. Furthermore, neurites preferred cells that overexpressed the largest but not the smallest tenascin- $C$ splice variant when given a choice between control cells and cells transfected with tenascin- $C$. The permissive guidance cues of large tenascin- $C$ expressed by cells were mapped to fnA-D. Using a combination of recombinant proteins corresponding to specific alternatively spliced FN-III domains and monoclonal antibodies against neurite outgrowth-promoting sites, we demonstrated that neurite outgrowth and guidance were facilitated by distinct sequences within fnA-D. Hence, neurite outgrowth and neurite guidance mediated by the alternatively spliced region of tenascin- $C$ are separable events that can be independently regulated.

Key words: tenascin-C; FN-III domain; alternatively spliced region; neurite guidance; neurite outgrowth; inert substrate; cellular substrate
Development of the nervous system is absolutely dependent on targeted growth of axons and dendrites. Not only must neuronal processes elongate to reach their correct destination (neurite outgrowth), but they must navigate in the proper direction (neurite guidance). Both neurite outgrowth (Smith et al., 1986) and guidance (Letourneau et al., 1994) are thought to be regulated by astrocyte-derived surface molecules. Among these molecules is tenascin-C, an extracellular matrix protein transiently expressed at the boundaries of migratory pathways in the developing cortex (Steindler et al., 1989) and reexpressed on glial scars in the adult CNS (Lochter et al., 1991; McKeon et al., 1991; Laywell et al., 1996). Based on its localization, tenascin-C was originally thought to form barriers to advancing neurites by stunting their outgrowth and/or deflecting them elsewhere (Steindler et al., 1989). However, functional studies in vivo (Gates et al., 1996; Gotz et al., 1997; Zhang et al., 1997) and in vitro (Faissner and Kruse, 1990; Lochter et al., 1991; Meiners and Geller, 1997) have demonstrated that tenascin-C can provide permissive, as well as inhibitory, cues for neuronal growth.

Tenascin-C is not a single molecule but is instead a family of alternatively spliced variants with potentially diverse actions

\footnotetext{
Received May 7, 1999; revised July 6, 1999; accepted July 13, 1999.

This work was supported by National Institutes of Health Grant R01 NS24168 to H.M.G. and National Institute of Environmental Health Sciences Exploratory Research Award RQ1610 to S.M. We thank Dr. Harold Erickson for helpful discussions and the gift of BHK cells, recombinant proteins, and polyclonal tenascin-C antibodies, Drs. Fransçoise Coussen and Ikramuddin Aukhil for the gift of recombinant proteins and rat fnB-D, Dr. Andreas Faissner for helpf ul discussions and the gift of monoclonal antibody J1/tn2, and Dr. Elizabeth M. Powell for helpful discussions.

Correspondence should be addressed to Dr. Sally Meiners, Department of Pharmacology, University of Medicine and Dentistry of New Jersey, Robert Wood Johnson Medical School, 675 Hoes Lane, Piscataway, NJ 08854.

Copyright (C) 1999 Society for Neuroscience $0270-6474 / 99 / 198443-11 \$ 05.00 / 0$
}

(Chung et al., 1996; Meiners and Geller, 1997; Gotz et al., 1997). Tenascin-C splice variants differ only in their number of fibronectin type-III (FN-III) domains; for example, the largest splice variant of human tenascin- $\mathrm{C}$ has seven alternatively spliced $\mathrm{FN}$ III domains [FN-III repeats A-D (fnA-D)] (Fig. 1) which are missing in the smallest. Phases of increased cell migration and axonal growth in the developing CNS have been closely correlated with expression of large but not small tenascin-C (Crossin et al., 1989; Steindler et al., 1989; Kaplony et al., 1991; Bartsch et al., 1992; Tucker, 1993), suggesting that fnA-D might facilitate cell and neurite motility during embryogenesis. Our own work demonstrated that fnA-D avidly promoted neurite outgrowth in vitro from a variety of neuronal types, by itself as a recombinant protein and also as part of large tenascin-C (Meiners and Geller, 1997; Meiners et al., 1999).

Our previous work suggests that neurite outgrowth and guidance may be separable events (Powell and Geller, 1999). We therefore used two complementary choice assays to investigate the hypothesis that fnA-D imparts distinct outgrowth and guidance cues. In one, growing neurites were allowed to choose between poly-L-lysine (PLL) and recombinant proteins corresponding to alternatively spliced and universal tenascin-C FN-III domains, as well as large and small tenascin-C splice variants. In the other, neurites were allowed to choose between transfected cells that overexpressed either large or small tenascin- $\mathrm{C}$ combined in heterogenous monolayers with untransfected cells. Neurites demonstrated a strong preference for fnA-D, which was masked in large tenascin- $\mathrm{C}$ on inert substrates but revealed in large tenascin-C on cellular substrates. Guidance and outgrowth cues were further localized to different sequences using monoclonal antibodies against neurite outgrowth-promoting sites and recombinant proteins corresponding to specific alternatively 


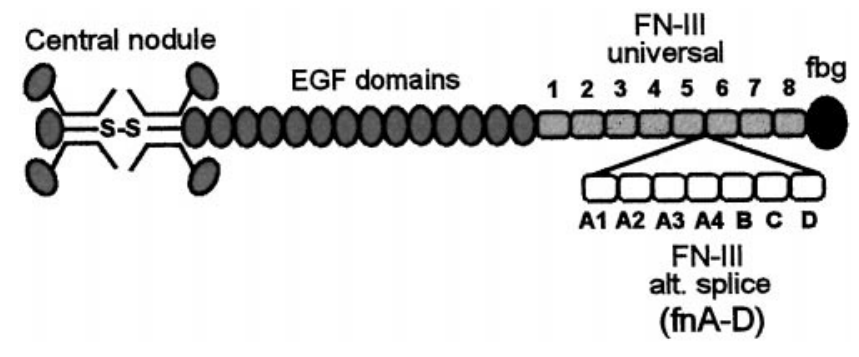

Figure 1. Multidomain structure of human tenascin-C. This diagram is adapted from Aukhil et al. (1993). The $\mathrm{N}$ termini of three arms are joined to form a trimer, and two trimers are connected via a disulfide bond to form a hexamer. Each arm consists of 14 EGF domains, 8-15 FN-III domains depending on alternative RNA splicing, and a single fibrinogen domain. The universal FN-III domains (fn1-5 and fn6-8) are present in all tenascin-C splice variants. The largest tenascin-C splice variant contains seven alternatively spliced FN-III domains (designated A1, A2, A4, $\mathrm{B}, \mathrm{C}$, and $\mathrm{D}$, or fnA-D), which are missing in the shortest splice variant.

spliced FN-III domains. Hence, neurite outgrowth and guidance can be independently regulated by the alternatively spliced region of tenascin-C.

\section{MATERIALS AND METHODS}

Proteins and antibodies. Transfected baby hamster kidney (BHK) cells, recombinant proteins expressed in bacteria, and rabbit polyclonal tenascin-C antibodies were gifts of Dr. Harold Erickson (Department of Cell Biology, Duke University Medical Center, Durham, NC). Splice variants of human tenascin-C were produced in the transfected cells (Aukhil et al., 1993). Native large and small tenascin-C were purified from culture supernatants of these cells by gelatin-Sepharose and hydroxyapatite chromatography (Aukhil et al., 1990; Erickson and Briscoe, 1995), followed by electroelution from nondenaturing gels (S. Meiners, unpublished data). Recombinant proteins expressed in bacteria (Aukhil et al., 1993) corresponded to the following: universal FN-III domains 1-5 and 6-8 (fn1-5 and fn6-8); fnA-D, the alternatively spliced FN-III domains of large tenascin-C; and fnA-D (-) C, the alternatively spliced domains minus FN-III domain $\mathrm{C}(\mathrm{fnC})$. Fn1-5, fn6-8, and fnA-D were produced using the PCR and cDNA isolated from BHK cells transfected with large tenascin-C as the template. FnA-D (-) $\mathrm{C}$ was produced using PCR and cDNA isolated from U251-MG glioma cells as the template. [U251-MG cells produce alternatively spliced transcripts of tenascin-C that contain fnA-D as well as fnA-D $(-)$ C, although the species that contains fnA-D predominates (Erickson and Bourdon, 1989).] Rabbit polyclonal full-length tenascin-C antibody was prepared against highly purified tenascin-C from U251-MG cells, which is almost entirely large tenascin-C (Erickson and Bourdon, 1989). Rabbit polyclonal antibodies against fn1-5 and fnA-D were prepared against the corresponding recombinant protein. All reagents cited correspond to the human protein.

Recombinant proteins corresponding to fnA1-A4, the N-terminal region of fnA-D, and fnB-D, the C-terminal region of fnA-D, were gifts of Drs. Harold Erickson and Fransçoise Coussen (University of Bordeaux, Bordeaux, France). Both of these correspond to the human protein.

Monoclonal antibody J1/tn2 against mouse tenascin-C was a gift of Dr. Andreas Faissner (Department of Neurobiology, University of Heidelberg, Heidelberg, Germany). The epitope for $\mathrm{J} 1 / \mathrm{tn} 2$ is contained on $\mathrm{fnD}$ of mouse tenascin-C (Gotz et al., 1996).

Chondroitin sulfate proteoglycan (CSPG) mixture isolated from embryonic chick brain (consisting primarily of neurocan, phosphacan, versican, and aggrecan) was obtained from Chemicon (Temecula, CA). Aggrecan was from Sigma (St. Louis, MO), and laminin-1 was from Life Technologies (Rockville, MD). Monoclonal antibody CS-56, which reacts with the glycosaminoglycan portion of native chondroitin sulfate proteoglycans, was from Sigma. Monoclonal antibody RT97 against neurofilament was from the Developmental Studies Hybridoma Bank (Iowa City, IA), and a polyclonal antibody against neurofilament 200 was from Sigma. Monoclonal antibody tenascin-IIIB, which recognizes an epitope in $\mathrm{fnB}$ of human tenascin-C, was from Chemicon.

Neuronal cell culture. Cerebellar granule neuronal cultures were prepared as described by Levi et al. (1984). Neuronal cultures were cultivated from postnatal day 8 (P8) rat pups. Brains were removed into a
Petri dish containing $5 \mathrm{ml}$ of BMEM with 2 M HEPES buffer (BMEMHEPES). Cerebella were removed, and meninges and blood vessels were peeled off and discarded to ensure minimal contamination from endothelial cells. Cerebella were then minced into fine pieces $(<0.5 \mathrm{~mm})$ with dissecting knives and incubated in BMEM-HEPES containing $0.025 \%$ trypsin for $10 \mathrm{~min}$ at $37^{\circ} \mathrm{C}$. After incubation, the trypsinization was halted by adding $1 \mathrm{ml}$ of BMEM containing $0.025 \%$ soybean trypsin inhibitor and $0.05 \%$ DNase I. The tissue was then gently triturated through a fire-polished Pasteur pipette until it was dispersed into a homogeneous suspension. The suspension was transferred into a fresh tube. DMEM-25 mM KCl-10\% heat-inactivated FCS (3-4 ml) was added to any remaining tissue clumps, and the trituration was repeated. Cells were then filtered through an ethanol-sterilized $40 \mu \mathrm{m}$ mesh and centrifuged for $10 \mathrm{~min}$ at $1500 \mathrm{rpm}$. The pellet of cerebellar granule neurons was resuspended in DMEM-25 mM KCl-10\% FCS and used for neurite guidance and neurite outgrowth assays as described below.

Neurite guidance assay. Neurite guidance is operationally defined as directed neurite movement that is significantly different from chance. The two most frequently used guidance assays are the stripe assay (Vielmetter et al., 1990) and the spot assay (Snow et al., 1991). However, in neither has neurite behavior been quantified. We therefore modified the spot assay to quantify the behavior of neurites at an interface created between PLL and tenascin-C FN-III recombinant proteins, native tenascin-C splice variants, or CSPGs. The PLL-protein interface was created by placing a $5 \mu \mathrm{l}$ drop of the protein of interest ( $300 \mathrm{~nm}$ in HBSS) in the center of a $12 \mathrm{~mm}$ PLL-coated glass coverslip. Coverslips in 24-well trays were incubated with the protein drop for $2 \mathrm{hr}$ at $37^{\circ} \mathrm{C}$, and excess protein solution was rinsed away with HBSS. Similar coating efficiencies between the tenascin-C splice variants and recombinant proteins $\left(\sim 5 \mathrm{pmol} / \mathrm{cm}^{2}\right)$ were verified by incubating entire coverslips with proteins conjugated to amine reactive fluorescein (Pierce, Rockford, IL). Coated proteins were removed after $2 \mathrm{hr}$ by adding 2\% SDS. The fluorescence of proteins bound to PLL-coated glass was then assessed in a Cytofluor II fluorescence microplate reader (PerSeptive Biosystems, Framingham, MA) as we have described previously for proteins bound to cellular monolayers (Meiners et al., 1999). In agreement with the results of others (Dorries et al., 1996; Fischer et al., 1997), no major differences in coating efficiencies could be observed.

Cerebellar granule neurons were plated onto the coverslips at a density of 60,000 neurons per well and cultured for $48 \mathrm{hr}$ in DMEM-25 mM $\mathrm{KCl}-10 \%$ FCS. At this time, coverslips were fixed with acetic acid/ ethanol (5\%:95\%) for $5 \mathrm{~min}$ at $-20^{\circ} \mathrm{C}$. After fixation, coverslips were rinsed in PBS ( $\mathrm{pH}$ 7.4, $0.14 \mathrm{M} \mathrm{NaCl}, 2.7 \mathrm{~mm} \mathrm{KCl}, 1.5 \mathrm{~mm} \mathrm{KH}_{2} \mathrm{PO}_{4}$, and $4.3 \mathrm{mM} \mathrm{NaHPO}_{4}$ ) and incubated with the appropriate primary antibody against the protein in the drop (polyclonal full-length tenascin-C antibody for native tenascin- $\mathrm{C}$ splice variants and recombinant proteins, or monoclonal antibody CS-56 for CSPGs) diluted 1:100 in PBS containing $10 \%$ FCS (PBS-serum). After rinsing in PBS, the coverslips were incubated with fluorescein-conjugated secondary antibodies diluted 1:100 in PBS-serum (goat anti-rabbit secondary antibodies for tenascin-C spots and goat anti-mouse secondary antibodies for CSPG spots) (OrganonTechnika Cappel, Durham, NC). The coverslips were again rinsed in PBS, and those containing tenascin-C spots were incubated with monoclonal antibody RT97 against neurofilament, followed by a rhodamineconjugated goat anti-mouse secondary antibody, whereas those containing CSPG spots were incubated with polyclonal antibody against neurofilament 200 , followed by a rhodamine-conjugated goat anti-rabbit secondary antibody. All primary and secondary antibody incubations were for $30 \mathrm{~min}$ at $4^{\circ} \mathrm{C}$. Coverslips were rinsed in PBS, followed by $\mathrm{ddH}_{2} \mathrm{O}$, and then mounted in Fluoromount-G (Southern Biotechnology, Birmingham, AL) on microscope slides. Nonspecific binding of secondary antibodies was controlled for by omitting the appropriate primary antibody in parallel cultures.

Cultures were examined using a Zeiss (Oberkochen, Germany) Axioplan microscope equipped with an epifluorescence illuminator with appropriate filter sets to visualize the fluorochromes. Images of the cultures were captured using a Macintosh (Apple Computers, Cupertino, CA) Quadra 700 with a Scion (Frederick, MD) LG-3 frame grabber board. Images were analyzed by counting the number of neurites on both sides of the PLL-protein interface that either remained on their substrate (by virtue of either stopping or turning at the interface) or crossed to the other side. A sample of 75 neurites was considered for each side of the interface for each condition. Only single, nonfasiculated neurites within $10 \mu \mathrm{m}$ of the protein-PLL interface were considered for the analysis. This distance was chosen because filopodia have been shown to extend 
10-50 $\mu \mathrm{m}$ (Gomez and Letourneau, 1994). In addition, only neurites moving toward the interface were counted (the angle between the neurite and the interface was $<90^{\circ}$ ), and no neurite whose soma was sitting on the interface was counted. The percentage of neurites that crossed from PLL to the protein of interest or from the protein to PLL was then assessed.

Neurite outgrowth assay. To investigate the neurite outgrowthpromoting properties of fnA-D versus fnA-D (-) C, PLL-coated glass coverslips in 24-well trays were incubated with recombinant proteins (300 $\mathrm{nm}$ in HBS) for $2 \mathrm{hr}$ at $37^{\circ} \mathrm{C}$. In some experiments, coverslips were incubated with a mixture of fnA-D and monoclonal antibody J1/tn2 (75 $\mu \mathrm{g} / \mathrm{ml})$. Excess protein solution was rinsed away with HBS, and cerebellar granule neurons were plated onto the coverslips at a density of 60,000 neurons per well and allowed to extend neurites for $48 \mathrm{hr}$ in DMEM-25 mM KCl-10\% FCS. The extent of neurite outgrowth was then determined via carboxyfluorescein diacetate (CFDA) labeling (Petroski and Geller, 1994). CFDA (Sigma) intensely stains the soma and all processes of cultured, living neurons. Images of the cultures were captured using a Macintosh Quadra 700 and analyzed with NIH Image software (available at http://rsb.info.nih.gov/). A sample of 100 neurons with processes equal to or greater than one cell soma was considered for each condition. The length of each primary process and its branches was measured for each neuron, and the total neurite length was calculated as the sum of the lengths of individual neurites.

Neurite guidance assay on cellular substrates. To investigate regulation of neurite guidance in a cellular context, we generated cellular interfaces between untransfected BHK cells, which express no tenascin-C, and transfected BHK cells, which overexpress either the largest or smallest tenascin-C splice variant (Aukhil et al., 1993), according to a modified method of Powell et al. (1997). First, transfected BHK cells were labeled with the red fluorescent cell linker PKH26 (Sigma) according to the manufacturer's instructions. This dye binds irreversibly within the membranes of cells by selective partitioning with no apparent transfer of the label to unlabeled cells (Ford et al., 1996). Single cell suspensions of transfected cells and untransfected cells were then mixed in a 1:10 ratio. The cell mixture was plated onto PLL-coated glass coverslips in 24-well trays at a density of $1 \times 10^{5}$ cells per coverslip. This density yielded confluent monolayers $24 \mathrm{hr}$ later with readily distinguishable "islands" of individual PKH26-labeled, transfected cells interspersed among the untransfected cells. The transfected cells were also readily distinguished from untransfected cells by tenascin-C immunoreactivity.

Cerebellar granule neurons were plated onto BHK monolayers in DMEM-25 mM KCl-10\% FCS and were allowed to extend neurites for $48 \mathrm{hr}$. At this time, neurons and their processes were labeled with CFDA. Images of the cultures were captured, and neurite behavior was analyzed on both sides of the interface formed between an untransfected cell and a transfected cell. The number of neurites that originated on an untransfected cell and either remained on the untransfected cell or crossed to a transfected cell was assessed, as was the number of neurites that originated on a transfected cell and either remained on the transfected cell or crossed to an untransfected cell. A sample of 75 neurites was considered for each of these conditions. Only neurites within $10 \mu \mathrm{m}$ of the interface were included in the analysis.

Antibody blocking experiments on cellular substrates. To investigate the role of specific FN-III sequences in the regulation of neurite guidance by cellular tenascin-C, blocking experiments were conducted using polyclonal antibodies against full-length tenascin-C, alternatively spliced domains fnA-D, and universal domains fn1-5. Monoclonal antibody $\mathrm{J} 1 / \mathrm{tn} 2$, which reacts within $\mathrm{fnD}$ of fnA-D, was also used in blocking experiments. Mixed monolayers containing untransfected and transfected BHK cells were incubated with $75 \mu \mathrm{g} / \mathrm{ml}$ antibody in DMEM-25 $\mathrm{mm} \mathrm{KCl}-10 \% \mathrm{FCS}$ for $1 \mathrm{hr}$ at $37^{\circ} \mathrm{C}$. Cerebellar granule neurons were plated onto the cells and cultured for $48 \mathrm{hr}$ in the presence of antibodies. Neurite behavior at the interface between transfected and untransfected cells was then evaluated.

Amplification of tenascin-C fragments by reverse transcription-PCR. For the identification and characterization of fnC-containing tenascin-C mRNA isoforms in vivo, PCR (Saiki et al., 1988) was performed on reverse-transcribed total RNA isolated from P3 rat cerebellum. Total RNA was isolated using the RNeasy mini kit according to the manufacturer's instructions (Qiagen, Santa Clarita, CA). Reverse transcription (RT) of total RNA was done using $10 \mu \mathrm{g}$ of RNA and random primers with or without reverse transcriptase according to the manufacturer's instructions (Amersham Pharmacia Biotech, Piscataway, NJ). Amplification of tenascin-C fragments was done using the following primers:
A1-5' (5' GAAGAAGTACCTTCTCTG 3'), C-5' (5' GAGGCCCTGCCCCTTCTGGAA $3^{\prime}$ ), C-3' (5' TGTAACAATCTCAGCCCTCAA $\left.3^{\prime}\right)$, and D-3' (5' TGTTGTTGCTATGGCACT 3'). A1-5' represents a sequence at the $5^{\prime}$ end of the first alternatively spliced exon (fnA1) of rat tenascin-C (LaFleur, 1994). C-5' represents a sequence at the $5^{\prime}$ end of alternatively spliced exon fnC of human tenascin-C, and $\mathrm{C}-3^{\prime}$ represents a sequence complementary to the $3^{\prime}$ end of human fnC. These primers are based on the published nucleotide sequence of the human protein (Siri et al., 1991) because the corresponding rat sequences are not known. D-3' represents a sequence complementary to the $3^{\prime}$ end of the last alternatively spliced exon (fnD) of rat tenascin-C (LaFleur et al., 1994).

The primer pair C-5'/C-3' was used for amplification of a presumptive rat fnC homolog. FnA-C and fnA-D were amplified using primer pairs A-5'/C-3' and A-5'/D-3', respectively. PCR was performed in the presence of $1.5 \mathrm{mM} \mathrm{MgCl}_{2}$ and $50 \mathrm{~mm} \mathrm{KCl}$ by repeating the cycle $\left(94^{\circ} \mathrm{C}\right.$ for $1 \mathrm{~min}, 50^{\circ} \mathrm{C}$ for $1 \mathrm{~min}$, and $72^{\circ} \mathrm{C}$ for $\left.2 \mathrm{~min}\right) 35$ times. The amplification products were then characterized by agarose gel (1\%) electrophoresis.

Western blot analysis of tenascin-C polypeptides. Expression of tenascin-C in P3 rat cerebellum was examined using Western blotting techniques. Cerebellar tissue was homogenized on ice in Laemmli sample buffer (Laemmli, 1970). Protein concentrations were determined using the Bio-Rad (Hercules, CA) DC protein assay. The homogenate $(20 \mu \mathrm{g})$ was subjected to SDS-PAGE $(6 \%)$ (Laemmli, 1970) and then transferred to nitrocellulose paper $(100 \mathrm{~mA}, 6 \mathrm{hr})$ (Towbin et al., 1979). Tenascin-C polypeptides were visualized as we have reported previously (Meiners and Geller, 1997) using polyclonal full-length tenascin antibody and an alkaline phosphatase-conjugated goat anti-rabbit secondary antibody (Sigma).

\section{RESULTS}

\section{The alternatively spliced region of tenascin-C provides permissive neurite guidance cues}

FnA-D avidly promotes neurite outgrowth from a variety of CNS neurons (Meiners and Geller, 1997). We therefore investigated whether fnA-D can also provide guidance cues to growing neurites. Rat cerebellar granule neurons were cultured for $48 \mathrm{hr}$ on PLL-coated glass coverslips containing spots of alternatively spliced or universal tenascin-C FN-III domains. The behavior of the neurites was then analyzed at the protein-PLL interface. Figure $2 A$ shows that cerebellar granule neurites demonstrated a strong preference for fnA-D when encountering an interface between fnA-D and PLL. The neurites (red) and the fnA-D (green)-PLL interface are visualized in Figure $2 \mathrm{~B}$. More than $80 \%$ of the neurites originating on PLL crossed to fnA-D, and $<20 \%$ of the neurites originating on fnA-D crossed to PLL. This was significantly different from results obtained with neurites growing across a control fluorescein-labeled BSA-PLL interface in which $\sim 50 \%$ of the neurites originating on PLL crossed to BSA and vice versa. The same 50:50 crossing ratio was observed for neurites growing across an imaginary interface, created by drawing an ink circle approximating the size of a $5 \mu$ l protein drop on the back of the PLL-coated coverslip (data not shown). The increased number of neurites crossing onto fnA-D indicates that the alternatively spliced region provides permissive neurite guidance cues. In contrast, universal FN-III domains fn1-5 and fn6-8 did not elicit neurite behavior, which differed significantly from the control.

Because fnA-D promotes neurite outgrowth as a recombinant protein and as a part of the largest tenascin- $\mathrm{C}$ splice variant (Meiners and Geller, 1997), we investigated its ability to guide neurites in the context of native tenascin-C. Neurites were allowed to choose between PLL and either the largest or smallest tenascin-C splice variant. We only assessed neurite behavior on the PLL side of the interface because very few neurons adhered to purified tenascin-C. Neurites consistently avoided both splice variants (Fig. 2A). This is in agreement with qualitative results of 

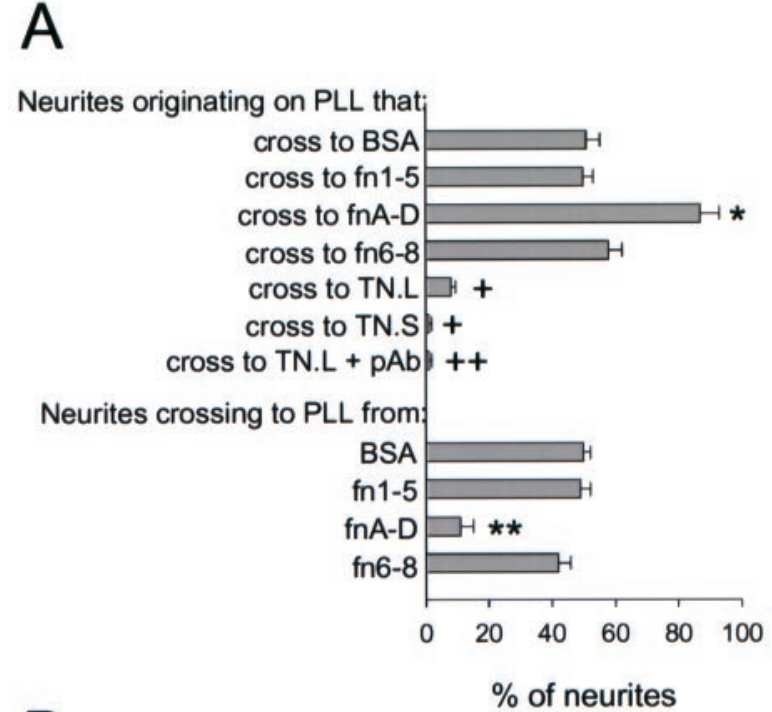

B

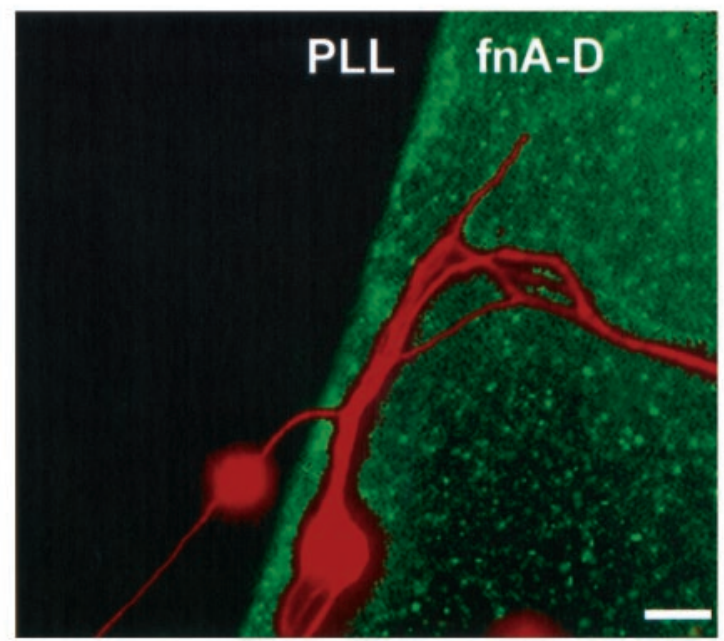

Figure 2. The alternatively spliced region of tenascin-C provides permissive neurite guidance cues. $A$, Cerebellar granule neurons were cultured for $48 \mathrm{hr}$ on PLL-coated coverslips containing spots of fn1-5, fnA-D, fn6-8, large tenascin-C (TN.L) or small tenascin-C (TN.S). The percentage of neurites that crossed from PLL to the protein spot and vice versa was then assessed. Bars represent the mean \pm SEM $(n=4)$. In control experiments, $51 \pm 4 \%$ of the neurites crossed from PLL to a fluoresceinlabeled BSA control, and $50 \pm 2 \%$ crossed from BSA to PLL. Neurite behavior at fn1-5-PLL or fn6-8-PLL interfaces did not vary significantly from the control. The percentage of neurites crossing from PLL to fnA-D was significantly higher than control (asterisk), and the percentage of neurites crossing from fnA-D to PLL was significantly lower than control (double asterisk) $(p<0.05$; Student-Newman-Keuls test). In contrast to fnA-D, the percentage of neurites crossing from PLL to large or small tenascin-C (crosses) was significantly lower than control $(p<$ 0.05 ; Student-Newman-Keuls test). A polyclonal antibody $(p A b)$ against fnA-D further reduced the percentage of neurites crossing to large tenascin-C (double cross); the reduction was significant $(p<0.05$; Student-Newman-Keuls test). $B$, Double immunocytochemistry was performed using a polyclonal antibody against full-length tenascin- $\mathrm{C}$, followed by a fluorescein-conjugated secondary antibody to detect fnA-D spots, and monoclonal antibody RT97 followed by a rhodamine-conjugated secondary antibody to detect neurons. Neurites on both sides of the PLLfnA-D interface showed a preference for fnA-D. Scale bar, $10 \mu \mathrm{m}$. others showing cerebellar granule neurite deflection by spots of tenascin-C (representing a mixture of splice variants) isolated from neonatal mouse brain (Dorries et al., 1996; Gotz et al., 1996). Therefore, the permissive guidance properties of fnA-D were masked by other parts of the tenascin-C molecule, indicating that tenascin- $C$ was more inhibitory on a molar basis than fnA-D was permissive. This observation was also reflected in doseresponse curves obtained for tenascin-C and fnA-D actions; the inhibitory effect of both tenascin-C splice variants and the permissive effect of fnA-D were dose-dependent with a tendency toward saturation at 100 and $300 \mathrm{~nm}$, respectively (data not shown). On the other hand, the smallest tenascin- $\mathrm{C}$ splice variant was always more repellant than the largest tenascin-C splice variant, with only $1-2 \%$ of the neurites crossing from PLL to small tenascin-C as opposed to $\sim 10 \%$ for large tenascin-C. Blocking large tenascin- $\mathrm{C}$ with a polyclonal antibody against fnA-D reduced the percentage of neurites that crossed to $1 \%$, showing that the difference in the results with the splice variants was attributable to the alternatively spliced region. Given that homogenous substrates of fn6-8 (Meiners and Geller, 1997) and large and small tenascin-C splice variants (Chiquet and Wehrle-Haller, 1994; Meiners and Geller, 1997) all promote neurite outgrowth, the results of this experiment indicate that the ability to facilitate neurite extension does not necessarily correlate with the ability to provide permissive neurite guidance cues.

\section{The alternatively spliced region overcomes tenascin-C boundaries to neurite advance}

We next investigated the hypothesis that a molar excess of the alternatively spliced region could overcome the inhibition of the rest of the tenascin- $\mathrm{C}$ molecule. To address this issue, we incubated PLL-coated coverslips with spots of protein consisting of a mixture of fnA-D and small tenascin-C. The concentration of small tenascin- $\mathrm{C}$ was held constant at $100 \mathrm{~nm}$, whereas that of fnA-D was increased from 100 to $400 \mathrm{~nm}$ (Fig. $3 A$ ). As in Figure 2 , only $1-2 \%$ of the neurites crossed onto small tenascin-C. This number increased to $8-10 \%$ for small tenascin- $\mathrm{C}$ in combination with $100 \mathrm{~nm}$ fnA-D, precisely the same percentage of neurites that crossed to large tenascin-C (Fig. 2). The percentage of neurites that crossed onto mixtures of small tenascin- $\mathrm{C}$ and fnA-D increased as the concentration of fnA-D was increased and reached the maximum with $300 \mathrm{~nm}$ fnA-D. This concentration resulted in $60-70 \%$ of the neurites crossing; larger concentrations of fnA-D did not further increase the percentage of neurites crossing. Hence, the concentration of fnA-D that is the most efficacious at providing neurite guidance cues by itself (Fig. 2) is also best to overcome the inhibitory guidance cues of small tenascin-C. Neurites more readily crossed onto $300 \mathrm{~nm}$ fnA-D (Fig. 2) than onto a mixture of $300 \mathrm{~nm}$ fnA-D and $100 \mathrm{~nm}$ small tenascin-C, indicating that fnA-D primarily mitigates, but does not entirely abolish, the inhibitory properties of small tenascin-C.

We also investigated the ability of the alternatively spliced region to overcome the inhibitory guidance cues of large tenascin-C. We found that a molar excess of fnA-D weakened the boundary formed by this tenascin-C splice variant $(100 \mathrm{nM})$; however, the maximal effect was observed with $200 \mathrm{~nm}$ fnA-D (Fig. 3B) rather than $300 \mathrm{~nm}$. The lower concentration of fnA-D necessary to overcome the boundaries formed by large as opposed to small tenascin-C probably reflects the fact that large tenascin- $\mathrm{C}$ already contains one fnA-D sequence, whereas small tenascin- $\mathrm{C}$ contains none. 

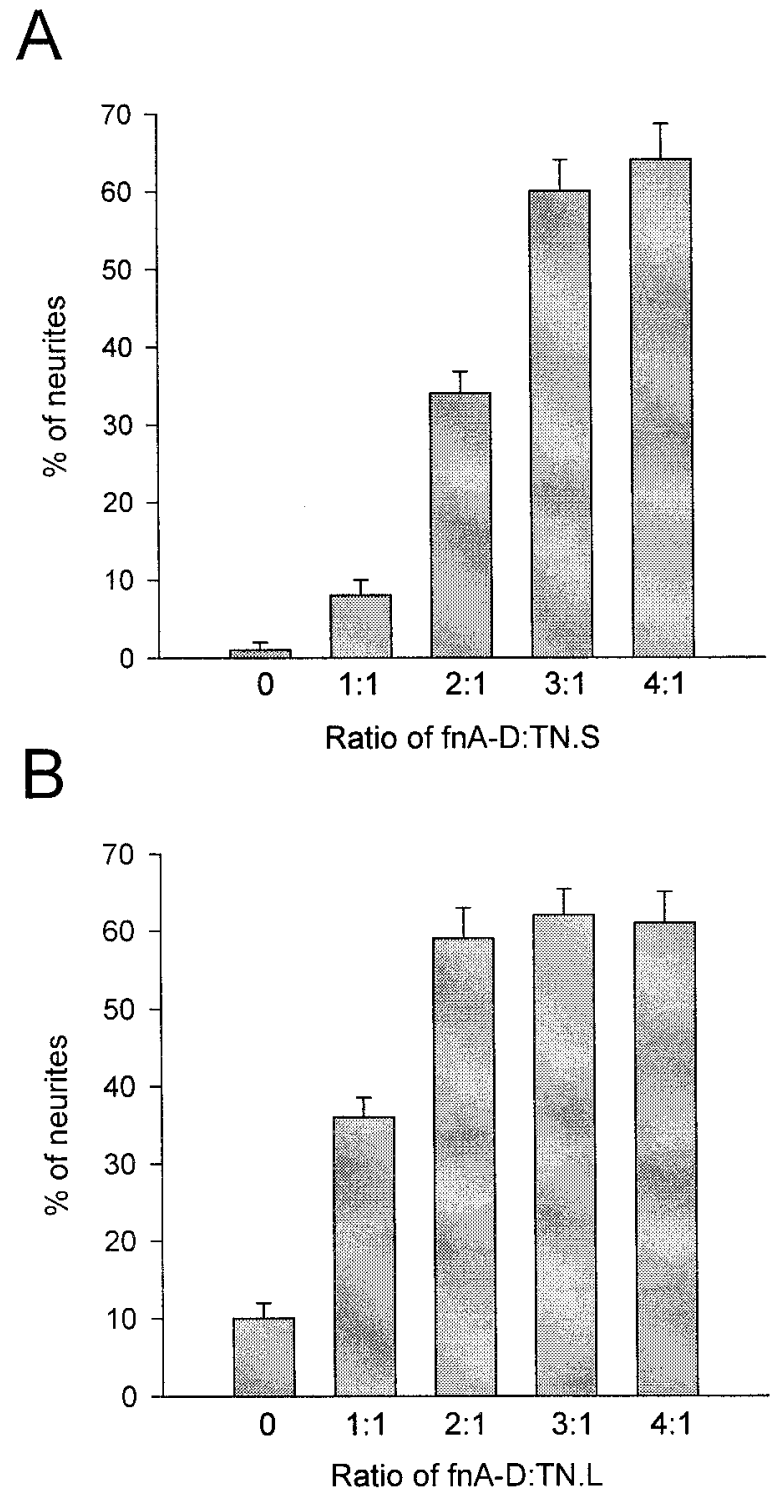

Figure 3. FnA-D overcomes tenascin-C boundaries to neurite advance. Cerebellar granule neurons were cultured for $48 \mathrm{hr}$ on PLL-coated coverslips containing spots of protein comprised of both small tenascin-C and fnA-D $(A)$ or large tenascin-C and fnA-D $(B)(n=3)$. The concentration of tenascin-C was held constant at $100 \mathrm{nM}$, and that of fnA-D was increased from $100 \mathrm{~nm}$ (a 1:1 ratio of fnA-D to tenascin-C) to $400 \mathrm{~nm}$ (a 4:1 ratio). The percentage of neurites crossing from PLL to the tenascinC-fnA-D spot increased with increasing concentrations of fnA-D. The maximal effect was observed with $300 \mathrm{~nm}$ fnA-D for small tenascin-C and $200 \mathrm{~nm}$ fnA-D for large tenascin-C.

\section{The alternatively spliced region overcomes CSPG boundaries}

Our next objective was to investigate whether the permissive guidance cues of fnA-D could also override inhibitory guidance cues provided by other types of molecules. We investigated its effects in combination with CSPGs, because CSPGs deflect neuronal processes in culture (Snow et al., 1990) and because tenascin-C and CSPGs are often coregulated on astrocytes (McKeon et al., 1991; Meiners et al., 1995; Powell et al., 1997). We first assessed neurite behavior at an interface formed between PLL and a mixture of CSPGs (Table 1) consisting primarily of neurocan, phosphacan, versican, and aggrecan. Because native
Table 1. FnA-D overcomes CSPG boundaries to neurite advance

\begin{tabular}{lccccc} 
& \multicolumn{2}{l}{$\begin{array}{l}\% \text { of neurites crossing } \\
\text { to CSPG mix }\end{array}$} & & \multicolumn{2}{l}{$\begin{array}{l}\% \text { of neurites crossing } \\
\text { to aggrecan }\end{array}$} \\
\cline { 2 - 3 } \cline { 5 - 6 } Addition & \multicolumn{2}{c}{ Concentration } & & Concentration & \\
\hline & $300 \mathrm{nM}$ & $1 \mu \mathrm{M}$ & & $300 \mathrm{nM}$ & $1 \mu \mathrm{M}$ \\
None & $1 \pm 1$ & & & $2 \pm 1$ & \\
fnA-D & $58 \pm 4$ & $59 \pm 4$ & & $64 \pm 4$ & $63 \pm 5$ \\
Laminin-1 & $9 \pm 1$ & $25 \pm 4$ & & $10 \pm 2$ & $23 \pm 3$ \\
fn6-8 & $12 \pm 2$ & $20 \pm 3$ & & $14 \pm 2$ & $21 \pm 4$ \\
\hline
\end{tabular}

Data represent the mean $\pm \operatorname{SEM}(n=4)$.

CSPGs with intact glycosaminoglycan side chains revealed a smear on SDS-PAGE gels and accurate molecular weights could not be assigned (data not shown), we used $10 \mu \mathrm{g} / \mathrm{ml}$ CSPG mixture in this experiment rather than a specified molar concentration. Neurites avoided the CSPG mixture, with only $1-2 \%$ crossing from PLL to the CSPGs. As with tenascin-C, neurons did not adhere to the CSPG mixture, and neurite behavior on the CSPG side of the interface was not assessed. When the CSPGs were combined with fnA-D (300 nM), $60 \%$ of the neurites now crossed onto the mixture of CSPGs and fnA-D. Larger concentrations of fnA-D did not further increase the percentage of neurites crossing.

We compared the effects of fnA-D with laminin-1, a potent promoter of neurite outgrowth. Laminin-1 was not nearly as effective in guiding neurites by itself ( $45 \%$ of the neurites crossed onto 300 nм laminin-1 (M.L.T. Mercado, unpublished data) as opposed to $80 \%$ for fnA-D) or in overcoming the CSPG barrier (only $\sim 10 \%$ of the neurites crossed onto the mixture of CSPGs and laminin-1). Increasing the concentration of laminin-1 to $1 \mu \mathrm{M}$ only increased the percentage of crossed neurites to $25-30 \%$. The experiment was repeated using a single CSPG, aggrecan, instead of a mixture, and similar results were obtained. FnA-D was more effective than laminin-1 in mitigating the inhibitory guidance cues of aggrecan. FnA-D was also more effective than fn6-8, another neurite outgrowth-promoting molecule (Meiners and Geller, 1997) that does not provide guidance information to neurites (Fig. 2A). Thus, fnA-D specifically overcomes boundaries to neurite advance that are formed by a variety of different CSPGs.

\section{Neurite guidance and neurite outgrowth are mediated by different sequences within fnA-D}

Facilitation of neurite outgrowth by fnA-D bound to inert substrates has been mapped to fnD (Gotz et al., 1996). We therefore explored this question: are neurite outgrowth and neurite guidance mediated by the same or different sequences within fnA-D? To do this, we evaluated the ability of monoclonal antibody J1/tn2 to alter neurite behavior in both neurite guidance and neurite outgrowth assays. This antibody specifically blocks the neurite outgrowth-promoting site within fnD (Gotz et al., 1996, 1997; Meiners et al., 1999). Spots of fnA-D or a mixture of fnA-D and $\mathrm{J} 1 / \mathrm{tn} 2$ were made in the center of PLL-coated coverslips, and neurite behavior was quantified at the interface. $\mathrm{J} 1 / \mathrm{tn} 2 \mathrm{did}$ not alter the percentage of neurites crossing from PLL onto fnA-D (Fig. $4 A$ ) or the percentage of neurites crossing from fnA-D to PLL (data not shown). Neurite outgrowth assays were then conducted to quantify process extension on PLL or homogenous substrates of fnA-D or a mixture of fnA-D and J1/tn 2 adsorbed to PLL-coated coverslips. Box-and-whisker plots of total neurite length are shown in Figure 4B. Boxes enclose 25th and 75th 
percentiles of each distribution and are bisected by the median; whiskers indicate 5th and 95th percentiles. As expected, neurites were considerable longer on fnA-D compared with PLL, and $\mathrm{J} 1 / \mathrm{tn} 2$ eliminated the promotion of neurite outgrowth by fnA-D. In control experiments, monoclonal antibody tenascin III-B, which reacts within $\mathrm{fnB}$ (Chemicon), failed to alter outgrowth or guidance by fnA-D. These results indicate that neurite guidance by $\mathrm{fnD}$ is regulated by a different sequence from that promoting neurite outgrowth.

To begin to localize neurite guidance site(s) within fnA-D to a particular region of the protein, cerebellar granule neurons were cultured for $48 \mathrm{hr}$ on PLL-coated coverslips containing spots of the following: fnA1-A4, the N-terminal portion of fnA-D; fnB-D, the C-terminal portion of fnA-D; or a mixture of fnA1-A4 and fnB-D (300 nм of each). Neurite behavior was then evaluated at the recombinant protein-PLL interface (Fig. 5). Only $20 \%$ of the neurites originating on the PLL side of a PLL-fnA1-A4 interface crossed onto fnA1-A4, whereas neurites originating on the fnA1-A4 side of the interface showed no bias for either PLL or fnA1-A4 (compare with neurite behavior at the BSA-PLL control interface in Fig. 2). This suggests that neurite behavior on one side of an interface cannot necessarily predict neurite behavior on the other side. Hence, neurites growing on PLL avoid fnA1-A4, but neurites growing on fnA1-A4 seem to "acclimate" to the molecule rather than opting to cross off of it. On the other hand, neurites on both sides of the interface showed a preference for fnB-D; the percentages of neurites crossing to fnB-D from PLL and to PLL from fnB-D were nearly identical to those observed for fnA-D (compare with Fig. 2). Hence, fnB-D mimicked the actions of fnA-D. An equimolar mixture of fnA1-A4 plus fnB-D also mimicked the actions of fnA-D, suggesting that the $\mathrm{C}$-terminal portion of fnA-D provides permissive neurite guidance cues and overcomes the inhibitory boundary formed by the N-terminal portion.

We next explored the hypothesis that fnC provides guidance cues to growing neurites. The rationale for this hypothesis was based on published work demonstrating that cerebellar granule neurites avoid rodent fnA-D recombinant proteins, which lack fnC (Gotz et al., 1996). We compared fnA-D with an fnA-D recombinant protein missing fnC (fnA-D (-) C) in neurite guidance and neurite outgrowth assays. Neurite behavior was quantified at fnA-D or fnA-D (-) C (300 nM)-PLL interfaces (Fig. $6 A$ ). As in Figure $2 A,>80 \%$ of the neurites crossed from PLL onto fnA-D. This was reduced to $\sim 25 \%$ for neurites crossing onto fnA-D (-) C. These data are consistent with the hypothesis that fnC provides permissive guidance cues, which overcome the barrier to neurite advance formed by fnA1-A4, the N-terminal portion of fnA-D (Fig. 5). As with fnA1-A4, neurites originating on fnA-D (-) C did not show a preference for either fnA-D $(-) \mathrm{C}$ or PLL. When neurite outgrowth assays were performed for neurons cultured on fnA-D or fnA-D (-) C adsorbed to PLL-coated coverslips (Fig. 6B), both proteins were found to be equally permissive to process extension compared with PLL alone. These results, along with those of Figure 5, imply that neurite guidance and neurite outgrowth by fnA-D are mediated through different alternatively spliced FN-III domains: fnC for neurite guidance and $\mathrm{fnD}$ for neurite outgrowth.

\section{FnA-D guides neurites in the context of cellular tenascin-C}

Work with purified substrates is informative but does not always predict the in vivo situation in which many molecules are present in a biological matrix (Meiners and Geller, 1997). We therefore investigated the ability of fnA-D to provide permissive neurite guidance cues in the context of tenascin-C expressed by a cell in which a neuron would normally encounter it. BHK cells transfected with the largest or smallest splice variant of human tenascin-C (BHK-TN.L or BHK-TN.S cells, respectively) were combined with control, untransfected BHK cells in a mixed monolayer. Cerebellar granule neurons were cultured on the mixed monolayer for $48 \mathrm{hr}$, and the behavior of neurites at the interface formed between transfected and control cells was assessed. Figure $7 A$ presents an image of the neuron-BHK coculture after double immunocytochemistry with antibodies against full-length tenascin-C to detect transfected cells and RT97 to

\section{A}

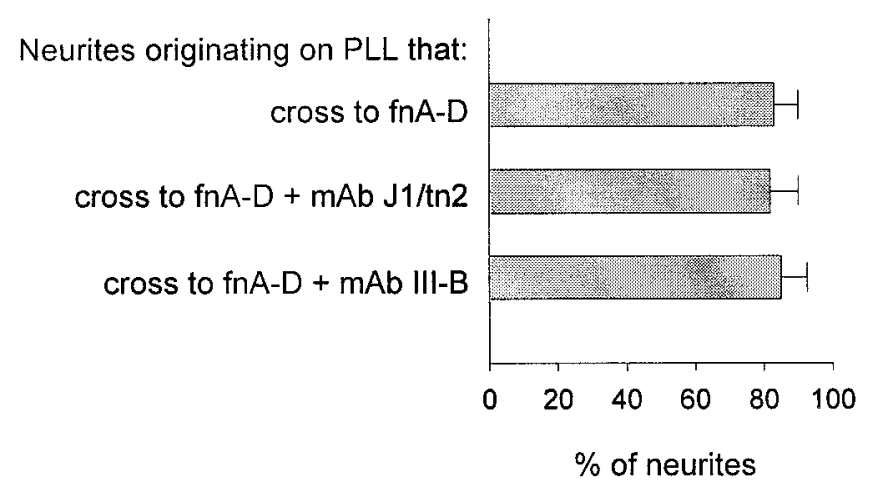

B

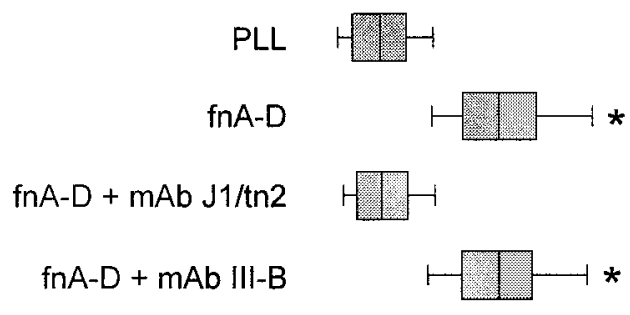

$0 \quad 50 \quad 100 \quad 150 \quad 200 \quad 250 \quad 300$

Total neurite length $(\mu \mathrm{m})$

Figure 4. The neurite outgrowth-promoting site in $\mathrm{fnD}$ does not mediate neurite guidance. $A$, Cerebellar granule neurons were cultured for $48 \mathrm{hr}$ on PLL-coated coverslips containing spots of fnA-D, a mixture of fnA-D, and monoclonal antibody (mAb) $\mathrm{J} 1 / \mathrm{tn} 2$, or a mixture of fnA-D and monoclonal antibody tenascin III-B (mAb III-B) $(n=4)$. J1/tn2, which reacts in $\mathrm{fnD}$, did not change the percentage of neurites that crossed from PLL to fnA-D, nor did mAb III-B, which reacts in fnB. $B$, Cerebellar granule neurons were allowed to extend neurites for $48 \mathrm{hr}$ on PLL-coated glass coverslips or PLL-coated glass coverslips to which fnA-D or mixtures of fnA-D and J1/tn2 or mAb III-B had been adsorbed. Distributions of the total neurite length are presented as a box-and-whisker plot. One representative experiment of four is shown. Boxes enclose 25th and 75th percentiles of each distribution and are bisected by the median; whiskers indicate 5th and 95th percentiles. Outgrowth was significantly greater on fnA-D (asterisk) and the fnA-D-mAb III-B mixture (cross) than on the PLL control $(p<0.05$; Kolmogorov-Smirnov test $)$; hence, mAb III-B had no effect on the neurite outgrowth-promoting properties of fnA-D. Outgrowth on the fnA-D-J1/tn2 mixture did not differ significantly from the PLL control; hence, J1/tn2 eliminated the neurite outgrowthpromoting qualities of fnA-D. 


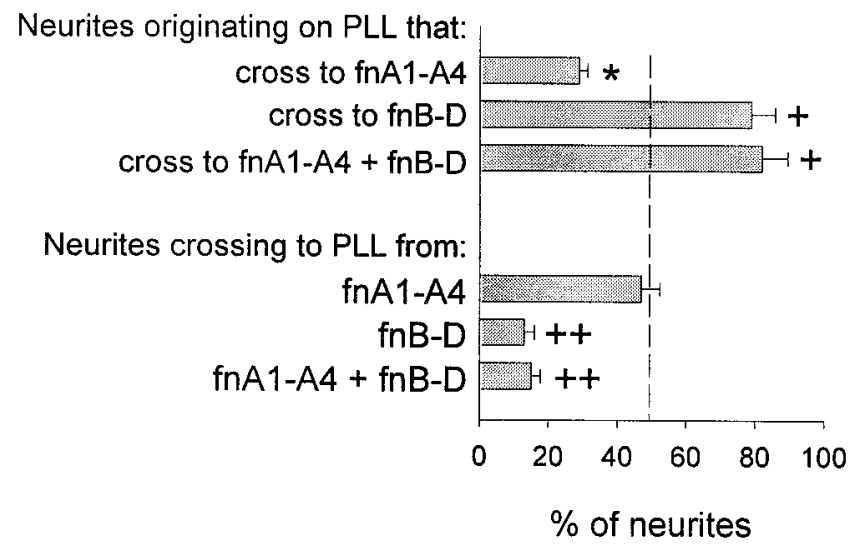

Figure 5. Neurite guidance is localized to the C-terminal portion of fnA-D. Cerebellar granule neurons were cultured for $48 \mathrm{hr}$ on PLLcoated coverslips containing spots of fnA1-A4, fnB-D, or a mixture of fnA1-A4 and fnB-D $(n=3)$. The dashed line indicates random neurite behavior at a control BSA-PLL interface. The percentage of neurites crossing from PLL to fnA1-A4 was significantly lower than control (asterisk) ( $p<0.05$; Student-Newman-Keuls test), whereas behavior for neurites originating on fnA1-A4 was more or less random. On the other hand, the percentage of neurites crossing from PLL to fnB-D or fnA1-A4 plus fnB-D was significantly higher than control (crosses), and the percentage of neurites crossing from fnB-D or fnA1-A4 plus fnB-D to PLL was significantly lower than control (double crosses) $(p<0.05$; StudentNewman-Keuls test).

detect neurons. Neurites crossed quite readily from control BHK cells to BHK-TN.L cells, but they avoided crossing from BHK cells to BHK-TN.S cells. Similar results were obtained using cerebral cortical neurons (data not shown). This is in contrast to results obtained with purified substrates of tenascin-C, which always formed barriers to neurites regardless of the splice variant present (Fig. 2).

We then quantified neurite behavior at the interface formed between transfected and control BHK cells (Fig. 7B). BHK-TN.L or BHK-TN.S cells were labeled with the membrane marker PKH26 to ensure that we were examining a cellular rather than a matrix boundary. Immunocytochemistry and Western blotting demonstrated that PKH26 labeling did not interfere with the expression of tenascin- $\mathrm{C}$ by the transfected cells (data not shown). Neurites demonstrated a preference for BHK-TN.L cells compared with control BHK cells. Approximately $70 \%$ of the neurites that originated on a BHK cell crossed to a BHK-TN.L cell, and only $20 \%$ of the neurites that originated on a BHK-TN.L cell crossed to a BHK cell. This was significantly different from neurite behavior observed at a control BHK-BHK interface created between BHK cells and PKH26-labeled BHK cells in which the percentage of neurites that crossed to and from a PKH26-labeled cell was $45-50 \%$. On the other hand, neurites demonstrated a preference for BHK cells over BHK-TN.S cells. The percentage of neurites that crossed from a BHK cell to a BHK-TN.S cell (20\%) was significantly lower than control, whereas the percentage of neurites that crossed from a BHKTN.S cell to a BHK cell $(60-65 \%)$ was significantly higher than control. Therefore, only small tenascin-C provides inhibitory neurite guidance cues when expressed by a BHK cell. This suggests that the alternatively spliced region included in large tenascin-C overcomes the barrier formed by the rest of the molecule by providing permissive neurite guidance cues of its own.

To ascertain that fnA-D does indeed provide permissive guidance cues in the context of a cellular matrix, a panel of antibodies
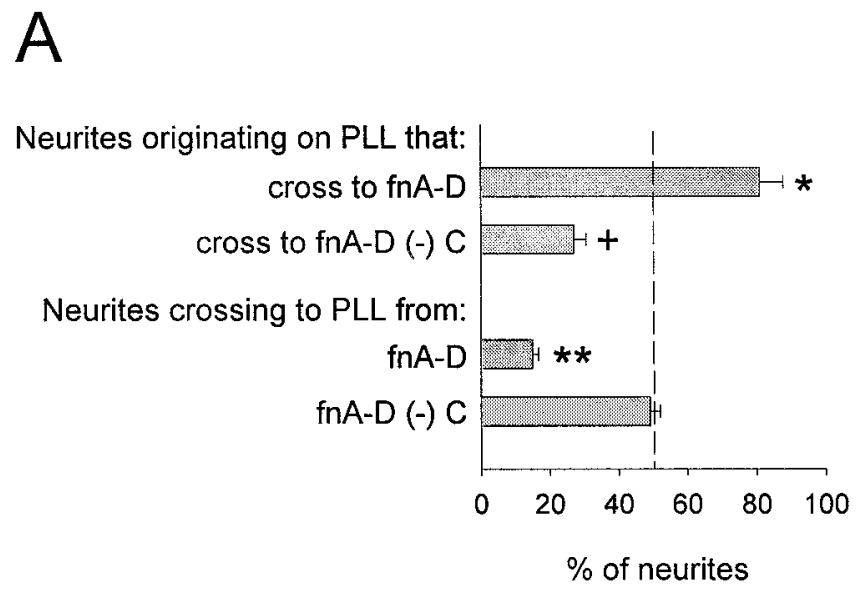

$B$

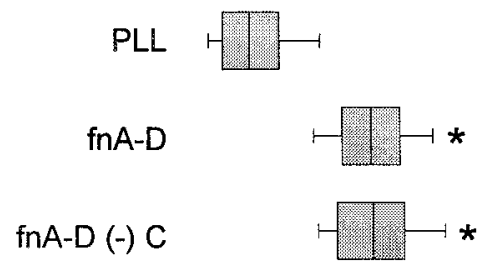

$0 \quad 50100150200250300$

Total neurite length $(\mu \mathrm{m})$

Figure 6. FnC is implicated in mediation of neurite guidance. A, Cerebellar granule neurons were cultured for $48 \mathrm{hr}$ on PLL-coated coverslips containing spots of fnA-D or fnA-D $(-) \mathrm{C})(n=3)$. Neurites on the PLL side of the interface showed a significant preference for fnA-D (asterisk) and a significant aversion for fnA-D $(-) \mathrm{C}$ (cross) $(p<0.05$; StudentNewman-Keuls test). Neurites on the protein side of the interface showed a significant preference for fnA-D (double asterisk) $(p<0.05$; Student-Newman-Keuls test) but demonstrated random behavior (dashed line) on fnA-D (-) C. B, Cerebellar granule neurons were cultured for $48 \mathrm{hr}$ on PLL-coated coverslips to which fnA-D or fnA-D (-) $\mathrm{C}$ had been adsorbed. One representative experiment of four is shown. FnA-D and fnA-D (-) C both significantly increased neurite outgrowth compared with PLL (asterisks) $(p<0.05$; Kolmogorov-Smirnov test); distributions of neurite length on fnA-D and fnA-D (-) C were the same.

against tenascin- $\mathrm{C}$ was tested for interference with neurite behavior at cellular interfaces (Fig. 8). The selection included polyclonal antibodies against full-length tenascin-C, fnA-D, fn1-5, and monoclonal antibody $\mathrm{J} 1 / \operatorname{tn} 2$. All of these antibodies cross-react with the largest tenascin-C splice variant on transfected BHK cells. As expected, the polyclonal antibody against fnA-D and monoclonal antibody J1/tn2 do not cross-react with the smallest tenascin-C splice variant, the fn1-5 antibody does not cross-react with fnA-D, and the fnA-D antibody does not crossreact with fn1-5 (Meiners and Geller, 1997).

The first antibody tested was a polyclonal antibody against full-length tenascin-C (Fig. $8 A$ ). In the presence of this antibody, the percentage of neurites that crossed from a BHK cell to a BHK-TN.S or a BHK-TN.L cell was indistinguishable from the control value obtained for neurites crossing from $\mathrm{BHK}$ cells to BHK cells (compare with Fig. $7 B$ ), as was the percentage of neurites that crossed from a BHK-TN.L or BHK-TN.S cell to a BHK cell (data not shown). This confirms that large and small 
A

\section{BHK/BHK-TN.L}

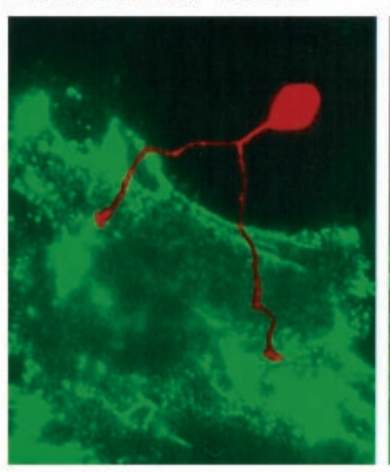

BHK/BHK-TN.S

B

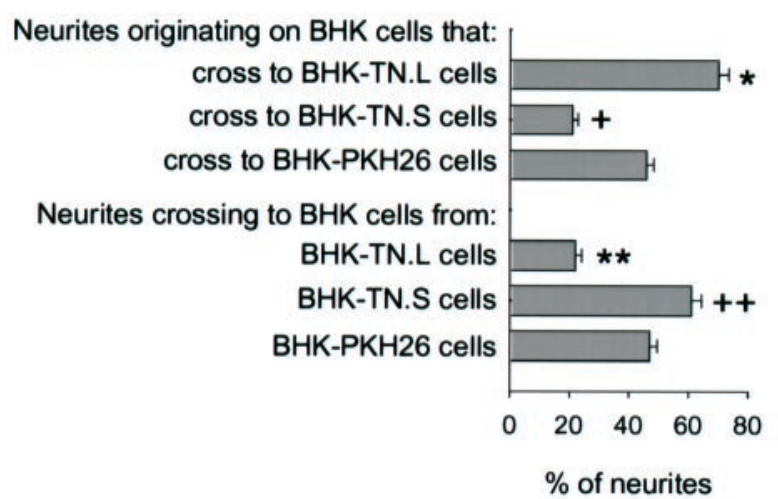

Figure 7. FnA-D guides neurites in the context of cellular tenascin-C. $A$, Cerebellar granule neurons were cultured for $48 \mathrm{hr}$ on a mixed monolayer of BHK cells and BHK-TN.L or BHK-TN.S cells. Double immunocytochemistry was performed using a polyclonal antibody against full-length tenascin-C, followed by a fluorescein-conjugated secondary antibody, and monoclonal antibody RT97, followed by a rhodamine-conjugated secondary antibody. Neurites crossed from BHK cells to BHK-TN.L cells but avoided BHK-TN.S cells. Scale bar, $12 \mu \mathrm{m}$. B, Neurite behavior at cellular interfaces was quantified $(n=4)$. In control experiments, $45-50 \%$ of the neurites crossed from BHK cells to PKH26-labeled BHK cells, and vice versa. The percentage of neurites that crossed from BHK cells to BHKTN.L cells was significantly higher than control (asterisk), and the percentage that crossed from BHK-TN.L cells to BHK cells was significantly lower (double asterisk) $(p<0.05$; Student-Newman-Keuls test). In contrast, the percentage of neurites that crossed onto BHK-TN.S cells was significantly lower than control (cross), and the percentage that crossed off was significantly higher (double cross) $(p<0.05$; Student-Newman-Keuls test).

tenascin-C were directly responsible for the permissive and inhibitory neurite guidance properties of BHK-TN.L and BHKTN.S cells, as opposed to some other factor produced by the transfected cells. The polyclonal antibody against fn1-5 did not alter the percentage of neurites that crossed to BHK-TN.L or BHK-TN.S cells, which was to be expected because a recombinant protein corresponding to this sequence did not provide neurite guidance cues (Fig. 2).

We then examined the effects of the two antibodies that react within the alternatively spliced region, polyclonal antibody against fnA-D and monoclonal antibody J1/tn2 (Fig. 8B). Neither of these antibodies altered the percentage of neurites that crossed
A
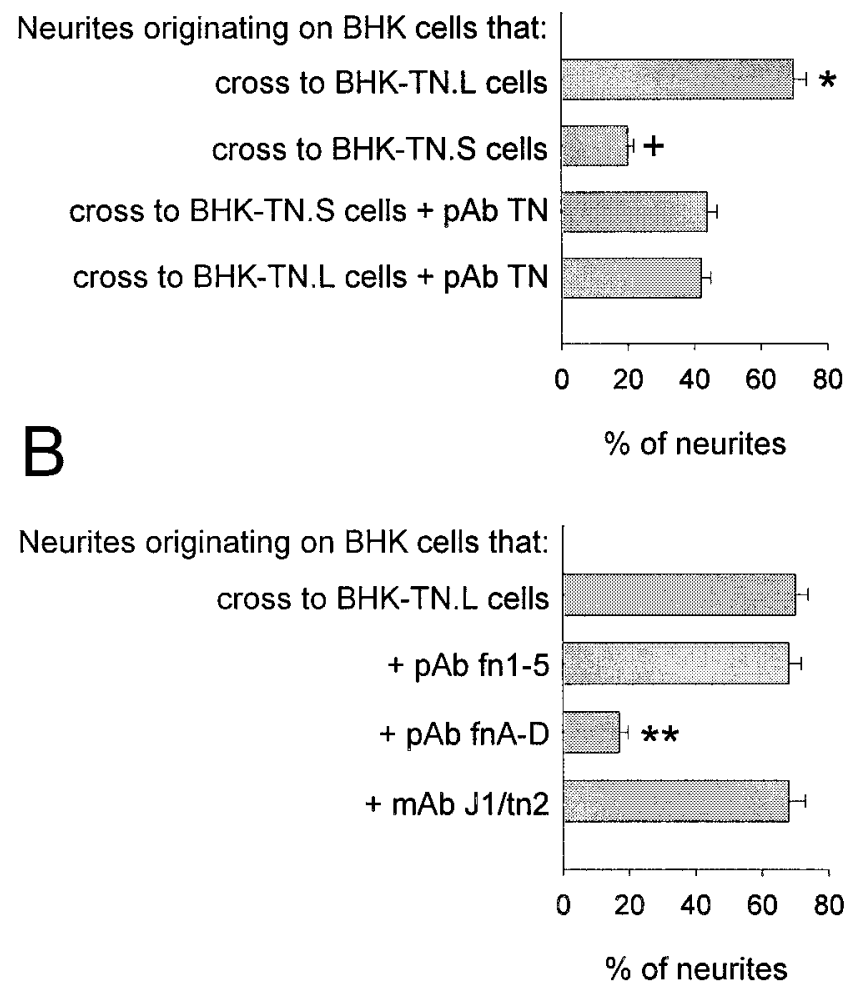

Figure 8. Neurite guidance in the presence of tenascin-C antibodies. $A$, Cerebellar granule neurons were cultured for $48 \mathrm{hr}$ on a mixed monolayer of BHK cells and BHK-TN.L or BHK-TN.S cells in the presence of a polyclonal antibody against full-length tenascin-C. The antibody significantly reduced the percentage of neurites that crossed from BHK cells to BHK-TN.L cells from $\sim 70$ to $50 \%$ (asterisk) and significantly increased the percentage of neurites that crossed to BHK-TN.S cells from $\sim 20$ to $50 \%$ (cross) $(p<0.05$; Student-Newman-Keuls test). $B$, Neurons were also cultured on a mixed monolayer of BHK cells and BHK-TN.L cells in the presence of polyclonal antibodies against fn1-5 or fnA-D, or monoclonal antibody $(m A b) \mathrm{J} 1 / \mathrm{tn} 2$. The fn1-5 antibody did not effect the percentage of neurites that crossed to BHK-TN.L cells, nor did J1/tn2. The fnA-D antibody significantly reduced the percentage of neurites that crossed to $\sim 20 \%$ (double asterisk) ( $p<0.05$; Student-Newman-Keuls test).

from BHK cells to BHK-TN.S cells (data not shown). However, the polyclonal antibody against fnA-D dramatically reduced the percentage of neurites that crossed to BHK-TN.L cells from 70 to $20 \%$. In the presence of this antibody, BHK-TN.L cells repelled neurites to the same extent as BHK-TN.S cells. Therefore, the permissive guidance cues of large tenascin-C expressed by transfected BHK cells could be mapped to the alternatively spliced region, suggesting that the ability of fnA-D to guide neurites is masked in purified tenascin-C (Fig. 2) but revealed in the BHK cell matrix. Monoclonal $\mathrm{J} 1 / \mathrm{tn} 2$ had no effect on the percentage of neurites crossing from BHK cells to BHK-TN.L cells. Hence, neurite-promoting sequences within fnA-D do not provide guidance cues to neurites, indicating that neurite outgrowth and guidance facilitated by the alternatively spliced region of tenascin-C are distinct events that can be independently regulated on cellular, as well as inert, substrates.

\section{An fnC homolog is expressed in developing rat cerebellum}

Our results implicate $\mathrm{fnC}$ and $\mathrm{fnD}$ in providing permissive neurite guidance and outgrowth cues to rat cerebellar granule neurites 


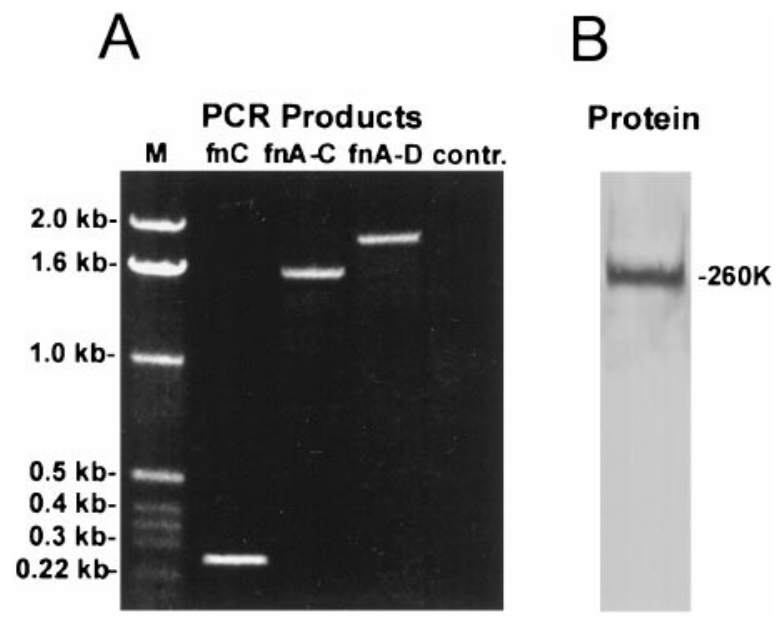

Figure 9. Analysis of fnC expression in developing rat cerebellum. $A$, PCR was performed on P3 rat cerebellar cDNA. Amplification was done using sense and antisense primers derived from the human $\mathrm{fnC}$ nucleotide sequence; a sense primer derived from the rat fnA1 sequence and an antisense primer derived from the human fnC sequence; or a sense primer derived from the rat fnA1 sequence and an antisense primer derived from the rat $\mathrm{fnD}$ sequence. One representative experiment of three is shown. The PCR products (designated fnC, fnA-C, and fnA-D) are depicted to the right of the marker $(M)$. They correspond in size to one, six, and seven FN-III domains (273, 1638, and 1911 bp, respectively). No products were obtained for cDNA synthesized without reverse transcriptase and then amplified with the fnC primers (contr.). B, Tissue homogenate from P3 rat cerebellum $(20 \mu \mathrm{g})$ was analyzed on Western blots probed with a polyclonal antibody against full-length tenascin-C, followed by an alkaline phosphatase-conjugated secondary antibody. One representative experiment of three is shown. Blots demonstrated one predominant tenascin-C polypeptide with $M_{\mathrm{r}}$ of 260,000.

(Figs. 5, 6). The presence of $\mathrm{fnD}$, but not $\mathrm{fnC}$, has been established in alternatively spliced forms of rat tenascin-C (LaFleur et al., 1994). We therefore conducted an RT-PCR analysis of the expression of the fnC exon in the early postnatal rat cerebellum, which is a time of active morphogenesis (Pigott and Kelly, 1984). Using primers based on the human tenascin-C sequence, a single PCR product of the expected size (273 bp) (LaFleur et al., 1994) was obtained (Fig. 9A). Amplification with a sense primer derived from the rat fnA1 sequence and an antisense primer derived from the human $\mathrm{fnC}$ sequence yielded a PCR product the size of 6 FN-III domains (1638 bp), and amplification with a sense primer derived from the rat fnA1 sequence and an antisense primer derived from the rat $\mathrm{fnD}$ sequence yielded a product the size of 7 FN-III domains (1911 bp). These results indicate that rat fnA-D contains a homolog of human $\mathrm{fnC}$ that is sixth in a series of seven alternatively spliced FN-III domains. This is consistent with reports for human (Siri et al., 1991), but not mouse, fnA-D, which only has six alternatively spliced FN-III domains (Dorries and Schachner, 1994; Joester and Faissner, 1999). In control experiments, no PCR products were revealed for cDNA synthesized in the absence of reverse transcriptase and then amplified with the fnC primers.

We did not conduct PCR experiments using combinations of primers to all of the alternatively spliced FN-III domains, and as such, our data do not exclude the possibility of shorter fnCcontaining mRNAs in the postnatal rat cerebellum [e.g., counterparts of the recently identified mouse fnC-containing mRNA splice variants containing two or four alternatively FN-III spliced domains (Joester and Faissner, 1999)]. On the other hand, Western blot analysis of P3 rat cerebellum with the full-length
tenascin-C polyclonal antibody only identified one predominant tenascin-C polypeptide with $M_{\mathrm{r}}$ of 260,000 (Fig. 9B). In agreement with the RT-PCR results (Fig. $9 A$ ), this polypeptide is of the correct size to represent the smallest reported rat tenascin-C splice variant $\left(M_{\mathrm{r}}\right.$ of 190,000) (Chiquet-Ehrismann et al., 1986) with the inclusion of seven alternatively spliced FN-III domains. Thus, our results support the presence of alternatively spliced FN-III domains $\mathrm{C}$ as well as $\mathrm{D}$ in the developing rat cerebellum, where they may provide guidance and growth cues to neurites.

\section{DISCUSSION}

The alternatively spliced FN-III region of tenascin-C, designated fnA-D, promotes neurite outgrowth as a substrate-bound molecule and also facilitates neurite guidance. Its permissive actions can be seen whether fnA-D is presented to neurons as a purified recombinant protein or as part of cellular tenascin- $\mathrm{C}$ in a biological matrix. Other molecules, such as the netrins (Kennedy et al., 1994; Serafini et al., 1994), also have strong effects on both the outgrowth and orientation of axons. However, in the case of the netrins, both processes are mediated through the same neuronal receptor, which probably interacts with the same functional domain of the netrin molecule (de la Torre et al., 1997). To our knowledge, fnA-D is the first molecule that independently facilitates neurite outgrowth and guidance through different sequences (located within alternatively spliced FN-III domains D and $\mathrm{C}$, respectively), providing strong evidence that outgrowth and guidance are separable events.

The fact the human fnA-D provided permissive guidance cues was somewhat surprising at first given published data with purified substrates of mouse fnA-D (Gotz et al., 1996). Mouse fnA-D facilitates process extension to the same extent as human fnA-D because of a common neurite outgrowth-promoting site within fnD (Gotz et al., 1996) but has been reported to form barriers to neurites. This implies that some sequence unique to human, but not mouse, fnA-D facilitates neurite guidance and that the common neurite outgrowth-promoting site is not involved. In agreement with this hypothesis, monoclonal antibodies against the neurite outgrowth-promoting site within $\mathrm{fnD}$ did not alter the ability of human fnA-D to guide neurites. We also found that neurites demonstrated a preference for human fnB-D in guidance assays but avoided rat fnB-D (data not shown). The rat fnB-D recombinant protein used in our assay and the mouse fnA-D recombinant protein used in the Gotz et al. (1996) study were both obtained via PCR using rodent tenascin-C cDNA as the template. However, it appears that these templates corresponded to naturally occurring tenascin- $\mathrm{C}$ variants, which lacked fnC. We found that a naturally occurring variant of human fnA-D lacking fnC also formed barriers to neurites instead of attracting them. Together, these data suggest that $\mathrm{fnC}$ is not only responsible for the permissive guidance cues of human fnA-D but overcomes inhibitory guidance cues provided by the rest of the molecule. It seems likely that rodent fnC will also impart permissive guidance cues to neurites, given that the sequence of mouse fnC displays 95\% identity with human fnC (Joester and Faissner, 1999).

In contrast to the permissive guidance cues provided by human fnA-D, purified substrates of all splice variants of human (Fig. 2) and mouse (Dorries et al., 1996; Gotz et al., 1996) tenascin-C are repulsive to advancing growth cones (Dorries et al., 1996). The growth cone-repelling properties have been attributed to the epidermal growth factor (EGF) domains (Dorries et al., 1996; Gotz et al., 1996). Therefore, on a molar basis, the EGF domains are more inhibitory than the alternatively spliced region is per- 
missive. However, a twofold to threefold molar excess of fnA-D significantly overcomes the boundary formed not only by tenascin-C but also by a variety of CSPGs. Much larger concentrations of laminin-1 were not nearly as effective. This is significant in that tenascin-C and CSPGs are upregulated on glial scars after injury (McKeon et al., 1991; Pindzola et al., 1993) in which they have been strongly implicated in failed axonal regeneration (Gates et al., 1996; Davies et al., 1997). Full recovery cannot occur after CNS injury unless axons are guided across the inhibitory terrain of the glial scar, suggesting a potential therapeutic role for fnA-D.

We have suggested previously that functions of the EGF domains of tenascin- $\mathrm{C}$ are obscured in cellular as opposed to purified tenascin-C, perhaps by cell-derived molecules binding to them or because of conformational restraints on cellular tenascin-C (Meiners and Geller, 1997). Specifically, the EGF domains promoted neurite outgrowth as purified recombinant proteins (Dorries et al., 1996; Gotz et al., 1996) but had no effect on outgrowth in the context of cellular tenascin-C (Gotz et al., 1997; Meiners and Geller, 1997). We found that antibodies directed against tenascin-C FN-III domains 6-8 and A-D blocked all regulation of neurite outgrowth by cellular tenascin- $C$; the EGF domains did not contribute (Meiners and Geller, 1997). We therefore reasoned that the boundary-forming properties of the EGF domains, in addition to the neurite-promoting properties, might be similarly attenuated in the cellular tenascin-C. If the EGF boundary was weakened in a biological matrix, the permissive guidance cues of fnA-D might then be revealed in the large tenascin-C splice variant. In support of this hypothesis, transfected $\mathrm{BHK}$ cells that overexpressed small tenascin- $\mathrm{C}$ formed a barrier to neurites, whereas cells that overexpressed large tenascin-C were attractive to neurites. However, more neurites crossed onto BHK-TN.S cells than onto purified small tenascin-C, and fewer neurites crossed onto BHK-TN.L cells than onto purified fnA-D (compare Figs. 3, 8). At the same time, in early experiments, neurites preferred BHK cells to which fnA-D was bound over BHK-TN.L cells. This suggests that the boundary-forming properties of the EGF domains of tenascin-C were partially but not totally eliminated in the BHK cell environment. A monoclonal antibody against the neurite outgrowthpromoting site within fnD did not affect the percentage of neurites that crossed to either BHK-TN.L or BHK-TN.S cells, demonstrating that neurite guidance and outgrowth facilitated by fnA-D were separable phenomena on cellular, as well as inert, substrates.

Although our results were obtained using BHK cells, it seems quite conceivable that guidance of neuronal processes by tenascin-C splice variants could vary with cell type. Different cell type-specific molecules might bind and mask different active sites for neurite guidance within the tenascin- $\mathrm{C}$ molecule, as we have seen for neurite outgrowth-promoting sites within the alternatively spliced region (Meiners et al., 1999). Alternatively, celltype specific molecules might provide neurite guidance cues of their own that compete with or override those of tenascin-C. For example, when the ratio of CSPGs to fnA-D was low, neurites were deflected, but as the ratio of fnA-D was increased, neurites crossed. Hence, the neuronal growth regulatory properties of tenascin-C or any other matrix protein can at best be discussed in a relative sense, and coordinated expression of specific tenascin- $\mathrm{C}$ splice variants by particular subsets of CNS cells may provide appropriate micro-environments for regulated changes in neuronal process outgrowth.
The number of tenascin-C mRNA splice variants identified in the developing CNS continues to increase (Dorries and Schachner, 1994; Joester and Faissner, 1999). FnD is present in the majority of these alternatively spliced mRNA variants, but $\mathrm{fnC}$ is found in only three: the largest variant, which contains all of the alternatively spliced FN-III domains (Dorries and Schachner, 1994; Joester and Faissner, 1999), and two smaller variants (Joester and Faissner, 1999). FnD-containing tenascin-C mRNA splice variants are expressed in a variety of non-neural, as well as neural, tissues in the developing rodent, whereas fnCcontaining variants are apparently restricted to the brain and spinal cord (Dorries and Schachner, 1994). This suggests that fnD may play a role in the development of many cell types and perform functions in addition to mediating neurite outgrowth, whereas fnC may play a more specific role during neural development. Significantly, fnC-containing tenascin-C mRNAs (Joester and Faissner, 1999) are found in postnatal mouse cerebella during periods of granule cell migration, and our own work has identified a putative fnC-containing mRNA and a corresponding high molecular weight tenascin-C polypeptide in early postnatal rat cerebella. Thus, the fnC domain is appropriately localized both spatially and temporally in rodents to provide guidance cues to neurons. On the other hand, fnC-containing tenascin-C mRNAs and polypeptides have also been identified in the developing chicken, but these are not found in the brain or spinal cord (Tucker et al., 1994). It is tempting to speculate that chicken and rodent fnC may serve different functions and that the evolutionary divergence between birds and mammals may be reflected in different activities for the same protein.

In summary, we have shown that the alternatively spliced region of human tenascin- $\mathrm{C}$ contains independent domains that promote either neurite outgrowth or neurite guidance. Extension of neurites is facilitated through alternatively spliced FN-III domain D, and orientation of growth is influenced by alternatively spliced FN-III domain C. Each of these processes can be regulated without affecting the other, indicating that neurite outgrowth and neurite guidance are distinct fundamental mechanisms of neuronal growth. Moreover, the ability of fnA-D to promote guidance was stoichiometric, and fnA-D could overcome inhibitory actions of both tenascin-C and CSPGs. Thus, fnA-D on its own might find applicability as a reagent to promote neurite growth in otherwise inhibitory environments.

\section{REFERENCES}

Aukhil I, Slemp CC, Lightner VA, Nishimura K, Briscoe G, Erickson HP (1990) Purification of hexabrachion (tenascin) from cell culture conditioned medium, and separation from a cell adhesion factor. Matrix 10:98-111.

Aukhil I, Joshi P, Yan Y, Erickson HP (1993) Cell- and heparin-binding domains of the hexabrachion arm identified by tenascin expression proteins. J Biol Chem 268:2542-2553.

Bartsch S, Bartsch U, Dorries U, Faissner A, Weller A, Ekblom P, Schachner M (1992) Expression of tenascin in the developing and adult cerebellar cortex. J Neurosci 12:736-749.

Chiquet M, Wehrle-Haller B (1994) Tenascin-C in peripheral nerve morphogenesis. Perspect Dev Neurobiol 2:67-74.

Chiquet-Ehrismann R, Mackie EJ, Pearson CA, Sakakura T (1986) Tenascin: an extracellular matrix protein involved in tissue interactions during fetal development and oncogenesis. Cell 47:131-139.

Chung C-Y, Murphy-Ullrich JE, Erickson HP (1996) Mitogenesis, cell migration, and loss of focal adhesions induced by tenascin-C interacting with its cell surface receptor, annexin II. Mol Biol Cell 7:883-892.

Crossin KL, Hoffman S, Tan SS, Edelman GM (1989) Cytotactin and its proteoglycan ligand mark structural and functional boundaries in somatosensory cortex of the early postnatal mouse. Dev Biol 136:381-392.

Davies SJ, Fitch MT, Memberg SP, Hall AK, Raisman G, Silver J (1997) 
Regeneration of adult axons in white matter tracts of the central nervous system. Nature 390:680-683.

de la Torre JR, Hopker VH, Ming GL, Poo MM, Tessier-Lavigne M, Hemmati-Brivanlou, Holt CE (1997) Turning of retinol growth cones in a netrin- 1 gradient mediated by the netrin receptor DCC. Neuron 19:1211-1244.

Dorries U, Schachner M (1994) Tenascin mRNA isoforms in the developing mouse brain. J Neurosci Res 37:336-347.

Dorries U, Taylor J, Xioa Z, Lochter A, Montag D, Schachner M (1996) Distinct effects of recombinant tenascin domains on neuronal cell adhesion, growth cone guidance, and neuronal polarity. J Neurosci Res 43:420-438.

Erickson HP, Bourdon MA (1989) Tenascin: an extracellular matrix protein prominent in specialized embryonic tissues and tumors. Annu Rev Cell Biol 5:71-92.

Erickson HP, Briscoe G (1995) Tenascin, laminin, and fibronectin produced by cultured cells. In: Extracellular matrix: a practical approach (Haralson MA, Hassell JR, eds), pp 187-198. Oxford: Oxford UP.

Faissner A, Kruse J (1990) J1/tenascin is a repulsive substrate for central nervous system neurons. Neuron 5:627-637.

Fischer D, Brown-Ludi M, Schulthess T, Chiquet-Ehrismann R (1997) Concerted action of tenascin-C domains in cell adhesion, anti-adhesion and promotion of neurite outgrowth. J Cell Sci 110:1513-1522.

Ford JW, Welling TH3, Stanley JC, Messina LM (1996) PKH26 and 125I-PKH95: characterization and efficacy as labels for in vitro and in vivo endothelial cell localization and tracking. J Surg Res 62:23-28.

Gates MA, Fillmore H, Steindler DA (1996) Chondroitin sulfate proteoglycan and tenascin in the wounded adult mouse neostriatum in vitro: dopamine neuron attachment and process outgrowth. J Neurosci 16:8005-8018.

Gomez TM, Letourneau PC (1994) Filopodia initiate choices made by sensory neuron growth cones at laminin/fibronectin borders in vitro. J Neurosci 14:5959-5972.

Gotz B, Scholze A, Clement A, Joester A, Schutte K, Wigger F, Frank R, Spiess E, Ekblom P, Faissner A (1996) Tenascin-C contains distinct adhesive, anti-adhesive, and neurite outgrowth promoting sites for neurons. J Cell Biol 132:681-699.

Gotz M, Bolz J, Joester A, Faissner A (1997) Tenascin-C synthesis and influence on axon growth during rat cortical development. Eur J Neurosci 9:496-506.

Joester A, Faissner A (1999) Evidence for combinatorial variety of tenascin-C isoforms and developmental regulation in the mouse central nervous system. J Biol Chem 274:17144-17151.

Kaplony A, Zimmermann DR, Fischer RW, Imhof BA, Odermatt BF, Winterhalter KH, Vaughan L (1991) Tenascin Mr 220000 isoform expression correlates with corneal cell migration. Development 112:605-614.

Kennedy TE, Serafini T, de la Torre JR, Tessier-Lavigne M (1994) Netrins are diff usible chemotropic factors for commissural axons in the embryonic spinal cord. Cell 78:425-435.

Laemmli UK (1970) Cleavage of structural proteins during the assembly of the head of bacteriophage T4. Nature 227:680-685.

LaFleur DW, Fagin JA, Forrester JS, Rubin SA, Sharifi BG (1994) Cloning and characterization of alternatively spliced isoforms of rat tenascin. Platelet-derived growth factor-BB markedly stimulates expression of spliced variants of tenascin mRNA in arterial smooth muscle cells. J Biol Chem 269:20757-20763.

Laywell ED, Friedman P, Harrington K, Robertson JT, Steindler DA (1996) Cell attachment to frozen sections of injured adult mouse brain - Effects of tenascin antibody and lectin perturbation of wound-related extracellular matrix molecules. J Neurosci Methods 66:99-108.

Letourneau PC, Snow DM, Gomez TM (1994) Regulation of growth cone motility by substratum bound molecules and cytoplasmic $\left[\mathrm{Ca}^{2+}\right]$. Prog Brain Res 103:85-98.

Levi G, Aloisi F, Ciotti MT, Gallo V (1984) Autoradiographic localization and depolarization-induced release of acidic amino acids in differentiating cerebellar granule cell cultures. Brain Res 290:77-86.

Lochter A, Vaughan L, Kaplony A, Prochiantz A, Schachner M, Faissner A (1991) J1/tenascin in substrate-bound and soluble form displays contrary effects on neurite outgrowth. J Cell Biol 113:1159-1171.
McKeon RJ, Schreiber RC, Rudge JS, Silver J (1991) Reduction of neurite outgrowth in a model of glial scarring following CNS injury is correlated with the expression of inhibitory molecules on reactive astrocytes. J Neurosci 11:3398-3411.

Meiners S, Geller HM (1997) Long and short splice variants of human tenascin differentially regulate neurite outgrowth. Mol Cell Neurosci 10:100-116.

Meiners S, Powell EM, Geller HM (1995) A distinct subset of tenascin/ CSPG-rich astrocytes restricts neuronal growth in vitro. J Neurosci 15:8096-8108.

Meiners S, Powell EM, Geller HM (1999) Neurite outgrowth promotion by the alternatively spliced region of tenascin- $\mathrm{C}$ is influenced by cell type-specific binding. Matrix Biol 18:75-87.

Petroski RE, Geller HM (1994) Selective labeling of embryonic neurons cultured on astrocyte monolayers with 5(6)-carboxyfluorescein diacetate (CFDA). J Neurosci Methods 52:23-32.

Pigott R, Kelly JS (1984) A cell surface antigen present on cultured cerebellar neurones appears to be transiently expressed during cerebellar development in the rat. Neurosci Lett 49:105-110.

Pindzola RR, Doller C, Silver J (1993) Putative inhibitory extracellular matrix molecules at the dorsal root entry zone of the spinal cord during development and after root and sciatic nerve lesions. Dev Biol 156:34-48.

Powell EM, Geller HM (1999) Dissection of astrocyte-mediated cues in neuronal guidance and process extension. Glia 26:73-83.

Powell EM, Fawcett JW, Geller HM (1997) Proteoglycans provide neurite guidance at an astrocyte boundary. Mol Cell Neurosci 10:27-42.

Saiki RK, Gelfand, DH, Stoffel S, Scharf SJ, Higuchi R, Horn GT, Mullis KB, Ehrlich HA (1988) Primer-directed enzymatic amplification of DNA with a thermostabile DNA polymerase. Science 239:487-491.

Serafini T, Kennedy TE, Galko MJ, Mirzayan C, Jessell TM, TessierLavigne M (1994) The netrins define a family of axon outgrowthpromoting proteins homologous to C. elegans UNC-6. Cell 78:409-424.

Siri A, Carnemolla B, Saginati M, Leprini A, Casari G, Baralle F, Zardi L (1991) Human tenascin: primary structure, pre-mRNA splicing patterns and localization of the epitopes recognized by two monoclonal antibodies. Nucleic Acids Res 19:525-531.

Smith GM, Miller RH, Silver J (1986) Changing role of forebrain astrocytes during development, regenerative failure, and induced regeneration upon transplantation. J Comp Neurol 251:23-43.

Snow DM, Lemmon V, Carrino DA, Caplan AI, Silver J (1990) Sulfated proteoglycans in astroglial barriers inhibit neurite outgrowth in vitro. Exp Neurol 109:111-130.

Snow DM, Watanabe M, Letourneau PC, Silver J (1991) A chondroitin sulfate proteoglycan may influence the direction of retinal ganglion cell outgrowth. Development 113:1473-1485.

Steindler DA, Cooper NG, Faissner A, Schachner M (1989) Boundaries defined by adhesion molecules during development of the cerebral cortex: the J1/tenascin glycoprotein in the mouse somatosensory cortical barrel field. Dev Biol 131:243-260.

Towbin H, Staehelin T, Gordon J (1979) Electrophoretic transfer of proteins from polyacrylamide gels to nitrocellulose sheets: procedures and some applications. Proc Natl Acad Sci USA 76:4350-4354.

Tucker RP (1993) The in situ localization of tenascin splice variants and thrombospondin $2 \mathrm{mRNA}$ in the avian embryo. Development 117:347-358

Tucker RP, Spring J, Baumgartner S, Martin D, Hagios C, Poss PM, Chiquet-Ehrismann R (1994) Novel tenascin variants with a distinctive pattern of expression in the avian embryo. Development 120:637-647.

Vielmetter J, Stolze B, Bonhoeffer F, Stuermer CA (1990) In vitro assay to test differential substrate affinities of growing axons and migratory cells. Exp Brain Res 81:283-287.

Zhang Y, Winterbottom JK, Schachner M, Lieberman AR, Anderson PN (1997) Tenascin-C expression and axonal sprouting following injury to the spinal dorsal columns in the adult rat. J Neurosci Res 49:433-450. 